\title{
CONSÓRCIO SORGO-SOJA. VII. SISTEMAS DE CORTE NO RENDIMENTO FORRAGEIRO DAS CULTURAS CONSORCIADAS
}

\author{
EDIVANDRO CORTE ${ }^{1}$ \\ PEDRO MILANEZ DE REZENDE ${ }^{2}$ \\ LUIS ANTÔNIO DE BASTOS ANDRADE ${ }^{3}$ \\ RENZO GARCIA VON PINHO \\ LEONARDO LINO GOMES ${ }^{4}$
}

\begin{abstract}
RESUMO - Com o objetivo de testar sistemas de corte na cultura de soja [Glycine $\max (\mathrm{L}$.) Merrill] e sorgo (Sorghum bicolor L. Moench) em consórcio na entrelinha, visando à produção de forragem, foi realizado este experimento no campo experimental da Universidade Federal de Lavras (UFLA) - utilizando o solo classificado como Latossolo Roxo Distrófico de textura argilosa, fase cerrado. O delineamento experimental empregado foi o de blocos casualizados, com três repetições em esquema fatorial $5 \times 2 \times 2+2+2$, constituído por 5 sistemas de corte, 2 cultivares de soja (CAC-1 e Conquista) e 2 híbridos de sorgo (AG 2002 e BR 601). No primeiro sistema, as plantas de sorgo e soja foram cortadas rente ao solo uma única vez no estádio farináceo do sorgo. No segundo, as plantas foram cortadas duas vezes, sendo o primeiro corte realizado a uma altura de $30 \mathrm{~cm}$ do colo da planta e o segundo após a rebrota, rente ao solo, ambos no estádio farináceo do sorgo. No terceiro sistema, os dois cor-
\end{abstract}

tes foram realizados a uma altura de $30 \mathrm{~cm}$ do colo da planta, no estádio farináceo do sorgo. No quarto sistema, um corte foi realizado no estádio vegetativo da soja $\left(\mathrm{V}_{8^{-}}\right.$ $\mathrm{V}_{12}$ ), a uma altura de $30 \mathrm{~cm}$ do colo da planta, e outro, após a rebrota no estádio $\mathrm{R}_{5}$, rente ao solo. No quinto sistema, o primeiro corte foi realizado no estádio vegetativo da soja $\left(\mathrm{V}_{8}-\mathrm{V}_{12}\right)$, a uma altura de $30 \mathrm{~cm}$ do colo da planta, e o segundo, após a rebrota, no estádio farináceo do sorgo, rente ao solo. A utilização dos cortes obedecendo ao estádio farináceo do sorgo (sistema 3) proporcionou os maiores rendimentos de massa verde total, matéria seca total e proteína bruta total. Os sistemas 2 e 3 foram os mais eficientes para produção de matéria verde e matéria seca, quando analisaram-se as duas culturas juntas, e para o rendimento de proteína bruta, os melhores sistemas foram 1, 2 e 3. A associação do sorgo AG 2002 e CAC-1 apresentou os maiores rendimentos de massa verde total, matéria seca total e proteína bruta total.

TERMOS PARA INDEXAÇÃO: Consórcio, sorgo, soja, forragem.

\section{SORGHUM AND SOYBEAN INTERCROPPING. VII. SYSTEMS OF CUTTING FOR INCREASING FORAGE OF INTERCROPPED SORGHUM-SOYBEAN}

\begin{abstract}
With the objective of testing the cutting systems of intercropped soybean [Glycine $\max$ (L.) Merrill] and sorghum (Sorghum bicolor L. Moench) on forage production, an experiment was carried out in a field at the Universidade Federal de Lavras - MG. The experiment was conducted on a Dusky Red Latosol of loamy texture. The experimental desing utilized was that of randomized blocks in factorial scheme $5 \times 2 \times 2$ $+2+2$ with three replications, constituted of 5 systems
\end{abstract}

of cutting, 2 soybean cultivars (CAC-1 and Conquista) and 2 hybrids of sorghum (AG 2002 and BR 601). In the first system the sorghum and soybean plants were cut closed to the soil only one time, at the farinaceous stage of sorghum. In the second, the plants were cut twice, the first cut at the height of $30 \mathrm{~cm}$ and the second, after regrowth, close to the soil, both being done at the farinaceous stage of sorghum. In the third system, the first two cuts were done at the plant height

\footnotetext{
1. Engenheiro Agrônomo, Pós-graduando do Departamento de Agricultura da UNIVERSIDADE FEDERAL DE LAVRAS/UFLA, Caixa Postal 37, 37200-000. Lavras, MG.

2. Engenheiro Agrônomo, D.Sc., Professor Titular do Departamento de Agricultura da UFLA (Bolsista do CNPq).

3. Engenheiro Agrônomo, D.Sc., Professor Adjunto do Departamento de Agricultura da UFLA (Bolsista do CNPq).

4. Acadêmico do $8^{\circ}$ período de Agronomia/UFLA (Bolsista do CNPq).
} 
of $30 \mathrm{~cm}$, at the farinaceous stage of sorghum. The fourth system was a cut done at the vegetative stage of the soybean $\left(\mathrm{V}_{8}-\mathrm{V}_{12}\right)$, at the plant height of $30 \mathrm{~cm}$, and the other, after regrowth, was done close to the soil, at the $\mathrm{R}_{5}$ stage. In the fifth system, the first cut was done at the vegetative stage of soybean $\left(\mathrm{V}_{8}-\mathrm{V}_{12}\right)$, at the plant height of $30 \mathrm{~cm}$, and the second, after regrowth, was done at the farinaceous stage of the sorghum, close to the soil. The cuttings at the farinaceous stage of sorghum (system 3) provided greater total green mass, dry matter and total crude protein. The association of sorghum AG2002 and CAC-1 showed a great increase in the amount of total green mass, dry matter and total crude protein.

INDEX TERMS: Intercropping, sorghun, soybean, forage.

\section{INTRODUÇÃO}

O consórcio é prática muito utilizada nas propriedades agrícolas; porém, a eficiência desse sistema está na dependência direta das culturas envolvidas, havendo a necessidade de uma complementação entre ambas para que o consórcio seja vantajoso em relação ao monocultivo. Em espécies como o milho e sorgo, a proteína é fator limitante para a produção de silagens, estando abaixo dos níveis exigidos pelos animais.

O cultivo consorciado da cultura do milho com a soja torna-se vantajoso quando o objetivo principal é a produção de forragens (Oliveira, 1986b). No sul do Estado de Minas Gerais, localiza-se uma das mais importantes bacias leiteiras do País. Nessa região, o consórcio sorgo-soja pode ser muito promissor, pois permite que a produção seja utilizada tanto para grãos como para forragem.

A forma mais usual da utilização do sorgo na alimentação de bovinos é na forma de silagem, pois constitui um volumoso de bom valor energético, porém deficiente em proteína. Uma das alternativas que o pecuarista pode utilizar para melhorar o valor nutritivo do alimento fornecido na época de escassez e diminuir os custos de suplementação protéica é a utilização de alimentos protéicos produzidos na propriedade. Nesse aspecto, o uso da soja ensilada juntamente com gramíneas tem se destacado, pois não diminui a produtividade forrageira, aumenta o teor de proteína da silagem e proporciona ganhos de peso significativamente maiores (Carneiro \& Rodriguez, 1978; Evangelista, 1980; Oliveira, 1986a). Essa espécie cultivada pode fornecer ainda forragem na forma de feno e/ou massa verde, conforme resultados obtidos por vários pesquisadores $(\mathrm{Re}-$ zende, 1984; Cardoso, 1985; Rezende \& Takahashi, 1990; Rezende, 1995).

Diante exposto, verifica-se que a planta de soja tem uma ampla utilização tanto na alimentação animal como na humana, além do largo uso industrial. Na atualidade, em que os custos de produção estão aumentando na pecuária leiteira, os agropecuaristas vêem na soja e sorgo uma alternativa para a produção de concentra- dos protéicos a custos menores na própria fazenda. Essas duas culturas poderão, após o corte, fornecer em conjunto mais forragem por unidade de área em consórcio do que quando cultivadas em monocultivo.

Com o presente trabalho teve-se por objetivo estudar diferentes sistemas de corte no rendimento forrageiro de híbridos de sorgo e cultivares de soja em consórcio na entrelinha.

\section{MATERIAL E MÉTODOS}

Os experimentos foram conduzidos no Departamento de Agricultura no Campus da Universidade Federal de Lavras-MG, a $21^{\circ} 14^{\prime}$ de latitude Sul e $45^{\circ} 00^{\prime}$ de longitude W.Gr., localizado a 918 metros de altitude em solo sob vegetação de cerrado, classificado como Latossolo Roxo Distrófico, durante o ano agrícola 1999/2000, e apresentaram os seguintes resultados: pH em água $=6,2, \mathrm{P}=10 \mathrm{mg} / \mathrm{dm}^{3}, \mathrm{~K}=100 \mathrm{mg} / \mathrm{dm}^{3}, \mathrm{Ca}=$ $3,9 \mathrm{cmol}_{\mathrm{c}} / \mathrm{dm}^{3}, \quad \mathrm{Mg}=1,3 \mathrm{cmol}_{\mathrm{c}} / \mathrm{dm}^{3}, \mathrm{Al}=0,0$ $\mathrm{cmol}_{\mathrm{c}} / \mathrm{dm}^{3}, \mathrm{H}+\mathrm{Al}=2,3 \mathrm{cmol}_{\mathrm{c}} / \mathrm{dm}^{3}, \mathrm{SB}=5,3$ $\mathrm{cmol}_{\mathrm{c}} / \mathrm{dm}^{3}, \mathrm{t}=5,3 \mathrm{cmol}_{\mathrm{c}} / \mathrm{dm}^{3}, \mathrm{~T}=7,3 \mathrm{cmol}_{\mathrm{c}} / \mathrm{dm}^{3}, \mathrm{~m}=$ $0 \%, \mathrm{~V}=69,9 \%$, matéria orgânica $=3 \%$, areia $=30 \%$, silte $=26 \%$ e argila $=44 \%$.

$\mathrm{O}$ delineamento experimental empregado foi o de blocos casualizados em esquema fatorial $2 \times 2 \times 5+$ $2+2$, com três repetições correspondendo a duas cultivares de soja (CAC-1 e Conquista), duas cultivares de sorgo (AG 2002 e BR 601) e cinco sistemas de corte. Esses materiais foram avaliados em todas as combinações possíveis duas a duas, em cinco sistemas de corte, sendo as épocas determinadas em função das culturas envolvidas. No primeiro sistema, as plantas de sorgo e soja foram cortadas rente ao solo, uma única vez, no estádio farináceo do sorgo. No segundo, as plantas foram cortadas duas vezes, sendo o primeiro corte realizado a uma altura de $30 \mathrm{~cm}$ do colo da planta e o segundo, após a rebrota, rente ao solo, ambos no estádio farináceo do sorgo. No terceiro sistema, os dois cortes foram realizados a uma altura de $30 \mathrm{~cm}$ do colo da planta, no estádio farináceo do sorgo. No quarto sistema, um corte 
foi realizado no estádio vegetativo da soja $\left(\mathrm{V}_{8}-\mathrm{V}_{12}\right)$, a uma altura de $30 \mathrm{~cm}$ do colo da planta, e outro após a rebrota, no estádio $R_{5}$ (Fehr \& Caviness, 1977), rente ao solo. No quinto sistema, o primeiro corte foi realizado no estádio vegetativo da soja $\left(\mathrm{V}_{8}-\mathrm{V}_{12}\right)$, a uma altura de $30 \mathrm{~cm}$ do colo da planta, e o segundo, após a rebrota no estádio farinácio do sorgo, rente ao solo. As datas de realização dos cortes em função dos tratamentos e sistemas de corte estão apresentados na Tabela 1.

Adicionalmente foi conduzido dois outros experimentos contíguos em blocos casualizados também com três repetições, para os respectivos monocultivos. Nesses, os cortes foram realizados uma única vez, rente ao solo, em forma convencional obedecendo às épocas isoladas de cada cultura, ou seja, $\mathrm{R}_{5}$ para a cultura da soja e grãos em estádio farináceo para o sorgo.

Os experimentos foram instalados em 10 de outubro de 1999, com semeadura simultânea das duas culturas. As parcelas de sorgo para o consórcio e monocultivo foram constituídas por três linhas espaçadas de $0,7 \mathrm{~m}$ entre fileiras, com 10,0 m de comprimento, sendo considerada como área útil apenas a fileira central. $\mathrm{O}$ desbaste foi realizado aos 25 dias após a emergência, procurando-se manter a população de 150.000 plantas/ha, para o sorgo.

A soja foi consorciada na entrelinha do sorgo, utilizando-se uma linha como área útil. No monocultivo da soja, as parcelas foram constituídas de 4 linhas de 5 $\mathrm{m}$ de comprimento, espaçadas de $0,50 \mathrm{~m}$, sendo consideradas as duas linhas centrais como área útil. O desbaste foi realizado aos 25 dias após a emergência, (Rezende \& Favoretto, 1987), deixando-se 20 plantas por metro linear, tanto em monocultivo como em consórcio para a cultura da soja. Antes da semeadura, foi realizada a inoculação das sementes de soja com Bradyrhizobium japonicum, na proporção de $0,5 \mathrm{~kg}$ de inoculante para $50 \mathrm{~kg}$ de sementes.

Para ambas as culturas, em condição de monocultivo, as adubações seguiram as recomendações feitas pela Comissão de Fertilidade do Solo do Estado de Minas Gerais (1989). Na cultura da soja, aplicaram-se 80 $\mathrm{kg}$ de $\mathrm{P}_{2} \mathrm{O}_{5} /$ ha e $40 \mathrm{~kg}$ de $\mathrm{K}_{2} \mathrm{O} / \mathrm{ha}$ e, nas parcelas de sorgo, foram aplicados $20 \mathrm{~kg}$ de N/ha, $120 \mathrm{~kg}$ de $\mathrm{P}_{2} \mathrm{O}_{5} / \mathrm{ha} \mathrm{e}$ $100 \mathrm{~kg}$ de $\mathrm{K}_{2} \mathrm{O} /$ ha por ocasião da semeadura. Utilizaram-se como fonte de $\mathrm{N}, \mathrm{P}_{2} \mathrm{O}_{5}$ e $\mathrm{K}_{2} \mathrm{O}$, sulfato de amônio super-simples e cloreto de potássio, respectivamente.

O corte das plantas foi realizado com roçadeira costal motorizada nas épocas relatadas anteriormente (Tabela 1). Os materiais foram avaliados separadamente, a fim de se obterem dados de contribuição de cada cultura individualmente. Posteriormente, somaram-se os rendimentos de sorgo e soja, sendo analisados os rendimentos de massa verde total $(\mathrm{kg} / \mathrm{ha})$, de matéria seca total (determinado a partir de amostra de $200 \mathrm{~g}$ de massa verde em estufa a $65^{\circ} \mathrm{C}$ até peso constante e convertido em $\mathrm{kg} / \mathrm{ha}$ ) e de proteína bruta total utilizando a mesma amostra usada na determinação da matéria seca, pelo método Kjeldahl e transformando posteriormente os dados para $\mathrm{kg} / \mathrm{ha}$.

Foram realizadas análises estatísticas combinadas (consórcio + monocultivo) para as características citadas anteriormente, utilizando-se o somatório das duas culturas (sorgo + soja). Para diferenciação das médias, foi utilizado o teste de Scott Knott a 5\%. Os resultados obtidos em consórcio foram comparados com os respectivos monocultivos de sorgo, pelo teste " $\mathrm{t}$ " de contraste.

TABELA 1 - Datas de realizações dos cortes em função dos tratamentos e sistemas de corte, UFLA, Lavras (MG), 2000.

\begin{tabular}{lccc}
\hline Tratamento & $\mathbf{1}^{\mathbf{0}}$ Corte & $\mathbf{2}^{\mathbf{0}}$ Corte & Sistema único \\
\hline Sistema N ${ }^{\circ}$ & - & - & $03 / 02 / 00$ \\
Sistema No & $03 / 02 / 00$ & $22 / 05 / 00$ & - \\
Sistema N 3 & $03 / 02 / 00$ & $22 / 05 / 00$ & - \\
Sistema No & $15 / 12 / 00$ & $15 / 03 / 00$ & - \\
Sistema No5 & $15 / 12 / 00$ & $15 / 03 / 00$ & - \\
CAC-1* & - & - & $01 / 03 / 00$ \\
Conquista* & - & - & $24 / 02 / 00$ \\
AG 2002* & - & - & $03 / 02 / 00$ \\
BR 601* & - & - & $03 / 02 / 00$ \\
\hline
\end{tabular}

\footnotetext{
* Monocultivo
} 


\section{RESULTADOS E DISCUSSÕES}

\section{Culturas do sorgo e soja}

O resumo das análises de variância para as características estudadas, utilizando o somatório dos rendimentos das características obtidas nas culturas do sorgo e soja em consórcio, encontra-se na Tabela 2, e os valores médios para essas características são apresentados nas Tabelas 3, 4 e 5.

Em trabalhos dessa natureza, nos quais buscase um melhor entendimento do sistema consorciado, torna-se necessário avaliar a performance das duas culturas conjuntamente. Neste estudo, foi utilizado o somatório dos valores individuais da massa verde, matéria seca e proteína bruta do sorgo + soja, pois essa mistura traduz as condições que ocorrem na prática de ensilagem em forragem oriunda do consórcio sorgo-soja.

\section{Massa verde e matéria seca total}

Analisando o rendimento conjunto das duas espécies, verifica-se que os sistemas de corte alteraram significativamente o rendimento de massa verde e matéria seca total (Tabela 2). Os sistemas 2 e 3 foram superiores aos demais, pelo fato de os dois cortes terem sidos realizados em função do sorgo (estádio farináceo do sorgo). Observa-se que o sistema 1 teve apenas um corte em função da cultura do sorgo, proporcionando queda nos rendimentos. Comparando a média do rendimento de massa verde total de um dos tratamentos superiores (sistema 3 ) em relação ao sistema 4 e 5, verifica-se uma superioridade de 126,41\% (42666 kg/ha) e $111,82 \%(40341 \mathrm{~kg} / \mathrm{ha}$, e para o rendimento de massa seca total, $204,72 \%$ (13864) e $205,62 \%$ (13884), respectivamente. Esses resultados foram devidos aos cortes dos sistemas 2 e 3 terem sidos realizados em função da gramínea, que sendo mais agressiva que a soja, proporcionou maior rendimento forrageiro. Resultado semelhante foi observado por Silva et al., 2000, que na mesma localidade também constataram maiores rendimentos com cortes realizados em função do sorgo. Resultados semelhantes de rendimentos de matéria seca em cultivo consorciados na entrelinha foram obtidos por Oliveira (1987), que verificou rendimento de 14,8 t/ha utilizando híbrido BR 601 com populações iguais à do presente trabalho.

Após efetuado o desdobramento da interação sistemas vs sorgo, verificou-se que o híbrido AG 2002 apresentou os maiores rendimentos nos sistemas 2 e 3 , e o BR 601, nos sistemas 2, 3 e 1 . Resultado semelhante foi observado com essa mesma interação para a matéria seca total. Nessa condição, os maiores rendimentos foram observados nos sistemas 2 e 3 . No consórcio, as cultivares de soja e os híbridos de sorgo não alteraram significativamente a massa verde total (Tabela 2). No caso da matéria seca total, as cultivares de soja e os híbridos de sorgo proporcionaram alterações significativas no rendimento dessa característica (Tabelas 2 e 4). A cultivar CAC-1, à semelhança do ocorrido com a massa verde, contribuiu para aumentar o rendimento forrageiro, superando a Conquista em 12,43\% (1659 $\mathrm{kg} / \mathrm{ha}$ ). No caso do sorgo, o híbrido AG 2002 foi o responsável pelo maior rendimento observado tanto no consórcio como no monocultivo, superando o AG

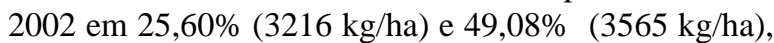
respectivamente.

Outro ponto a ser considerado é a interação consórcio vs monocultivo para a matéria seca total, que também foi significativa (Tabela 2). Na média, os sistemas consorciados $(14172 \mathrm{~kg} / \mathrm{ha})$ superaram o monocultivo (9045 kg/ha) em 56,68\% (5127 kg/ha), o que também foi verificado para massa verde e traduz-se numa das principais vantagens desse sistema. Aumentos no cultivo consorciado em relação ao monocultivo também foram constatados por Oliveira (1986a) e Rezende (1995), que observaram acréscimos de 5,43 e $6,25 \%$, respectivamente, quando o consórcio foi realizado na linha. Ao se analisar as combinações consorciadas, verifica-se que os maiores rendimentos de massa verde e matéria seca total que diferiram estatisticamente dos respectivos monocultivos do sorgo foram obtidos nos sistemas 1, 2 e 3 . Nessa situação, a combinação AG 2002 x CAC-1 nos sistemas 3 e 2, à semelhança do que ocorreu com a massa verde total, apresentou os maiores rendimentos (Tabela 3 e 4).

Nos sistemas consorciados, como é o caso deste ensaio, o rendimento de matéria seca da leguminosa torna-se importante, pois ela contribui para um incremento no rendimento total, sem proporcionar decréscimos significativos por efeito de competição na gramínea, quando consorciada na entrelinha. Mesmo ocorrendo uma ligeira diminuição da produção da gramínea nesse componente, quando se faz o consórcio das duas espécies na linha ou na entrelinha, há uma compensação por parte da leguminosa na melhoria da qualidade promovida por essa espécie forrageira no material a ser ensilado, justificando o seu uso nos sistemas consorciados (Carneiro \& Rodriguez, 1978, 1980; Rezende, 1995). 
TABELA 2 - Resumo da análise de variância combinada das características rendimento de massa verde total, matéria seca total e proteína bruta total de sorgo e soja, obtidas no ensaio de efeitos de diferentes sistemas de corte e no rendimento forrageiro em consórcio e monocultivo, no ano agrícola 1999/00. UFLA, Lavras-MG, 2000.

\begin{tabular}{lcccc}
\hline \multirow{2}{*}{ F.V. } & G.L. & \multicolumn{3}{c}{ Quadrados Médios } \\
\cline { 3 - 5 } & & Massa Verde & Matéria Seca & Proteína \\
\hline Entre Consórcio & 19 & $136.662 .822,00$ & $139.348 .853,33^{* *}$ & $337.097 .68 * *$ \\
Sistema & 4 & $540.464 .922,00^{* *}$ & $580.412 .572,08^{* *}$ & $1.289 .448,02^{* *}$ \\
Soja & 1 & $292.180 .320,26$ & $43.244 .664,06 * *$ & $253.500,00$ \\
Sorgo & 1 & $169.117 .133,00$ & $146.321 .920,06 * *$ & $282.083,00$ \\
Soja x Sorgo & 1 & $10.560,26$ & $204.166,66$ & $47.489,06$ \\
Sistema x Soja & 4 & $104.427 .473,59$ & $7.084 .994,31$ & $73.560,00$ \\
Sistema x Sorgo & 4 & $353.412 .962,26 * *$ & $21.230 .160,31 * *$ & $52.368,97$ \\
Sistema x Soja x Sorgo & 4 & $134.906 .830,26$ & $3.099 .505,58$ & $40.068,60$ \\
Entre Monocultivo & 1 & $429.260 .416,66 *$ & $19.063 .837,50 *$ & $28.290,66$ \\
Consórcio vs Monocultivo & 1 & $681.053 .674,93 *$ & $145.991 .466,60 * *$ & $2.393 .094,47 * *$ \\
Erro Médio & 40 & $96.300 .993,55$ & 4.486 .453 .05 & $90.866,29$ \\
\hline CV $(\%)$ & & 18 & 15 & 23 \\
\hline
\end{tabular}

**Significativo 1\%; * Significativo $5 \%$

TABELA 3 - Resultados médios de massa verde total de soja e sorgo (kg/ha) obtidos no ensaio de efeitos de diferentes sistemas de corte, na avaliação da capacidade de rebrota das plantas sobre o rendimento forrageiro em consórcio e monocultivo, no ano agrícola 1999/00. UFLA, Lavras-MG, 2000.

\begin{tabular}{lcccccc}
\hline \multicolumn{1}{c}{ Tratamento } & Sistema 1 & Sistema 2 & Sistema 3 & Sistema 4 & Sistema 5 & Mëdia \\
\hline AG 2002 x CAC-1 & $65250^{\mathrm{ns}}$ & $92333^{* *}$ & $96916^{* *}$ & $30333^{\mathrm{ns}}$ & $41150^{\mathrm{ns}}$ & 65196 \\
AG 2002 X Conquista & $70000^{*}$ & $73906^{* *}$ & $79833^{* *}$ & $33300^{\mathrm{ns}}$ & $42950^{\mathrm{ns}}$ & 59998 \\
BR 601 x CAC-1 & $63000^{* *}$ & $70333^{* *}$ & $66583^{* *}$ & $38266^{\mathrm{ns}}$ & $30783^{\mathrm{ns}}$ & 53793 \\
BR 601 x Conquista & $54916^{* *}$ & $67000^{* *}$ & $62333^{* *}$ & $33100^{\mathrm{ns}}$ & $29416^{\mathrm{ns}}$ & 49353 \\
\hline AG 2002 x Soja & $67625 \mathrm{~B}$ & $83120 \mathrm{~A}$ & $88375 \mathrm{~A}$ & $31816 \mathrm{C}$ & $42050 \mathrm{C}$ & $62597 \mathrm{a}$ \\
BR 601 x Soja & $58958 \mathrm{~A}$ & $68666 \mathrm{~A}$ & $64458 \mathrm{~A}$ & $35683 \mathrm{C}$ & $30100 \mathrm{C}$ & $51573 \mathrm{a}$ \\
\hline CAC-1 x Sorgo & 64125 & 81333 & 81750 & 34300 & 35966 & $59495 \mathrm{a}$ \\
Conquista X Sorgo & 62458 & 70453 & 71083 & 33200 & 36183 & $54675 \mathrm{a}$ \\
\hline Média & $63291 \mathrm{~B}$ & $75893 \mathrm{~A}$ & $76416 \mathrm{~A}$ & $33750 \mathrm{C}$ & $36075 \mathrm{C}$ & 57085 \\
\hline Monocultivo & & & & & \\
AG 2002 & $54166 \mathrm{a}$ & & & & \\
BR 601 & $37250 \mathrm{~b}$ & & & & \\
\hline Média & 45708 & & & & \\
\hline
\end{tabular}

Médias seguidas pela mesma letra, minúscula na coluna e maiúscula na linha, não diferem entre si pelo teste de Scott Knott a $5 \%$ de probabilidade.

*,** e ns - Contraste de "t'" entre consórcio e monocultivo do sorgo, significativo a 5\%, 1\% e nãosignificativo, respectivamente. 


\section{Rendimento de proteína bruta total}

De acordo com a (Tabela 2), verifica-se efeito significativo do fator sistema de corte. Observa-se uma superioridade dos sistemas 1, 2 e 3 em relação aos sistemas 4 e 5 (Tabela 5). Levando em consideração que as cultivares de soja e os híbridos de sorgo não alteraram significativamente o rendimento total de proteína, as diferenças observadas entre os vários sistemas de corte ficam creditadas à época de corte das culturas, conforme já relatado anteriormente. Independente do sistema de corte utilizado, os rendimentos médios de proteína bruta total são semelhantes aos observados por Rezende (1995) com consórcio milho-soja, e por Silva et al. (2000), que obtiveram valores na média dos sistemas de 1049 e $1195 \mathrm{~kg} / \mathrm{ha}$ de proteína.

As cultivares de soja e os híbridos de sorgo não alteraram significativamente o rendimento de proteína total (Tabela 2). Da mesma maneira como ocorreu para massa verde e matéria seca total, o rendimento de pro- teína total também foi alterado significativamente em função do consórcio vs monocultivo. Em média, os tratamentos consorciados superaram o monocultivo em $92,80 \%$ (657 kg/ha), o que comprova mais uma vez a eficiência do sistema consorciado sobre o monocultivo. Para essa característica, resultados positivos de incremento de proteína já eram esperados, pois as leguminosas, principalmente a soja, têm comprovada sua vantagem de incrementar o teor de proteína do material ensilado, em condição de consórcio com gramínea. Resultados semelhantes foram observados por vários autores (Carneiro \& Rodriguez, 1980; Evangelista, 1980; Carvalho, 1993; Rezende, 1995; Silva, 1998), que são unânimes em afirmar a vantagem dos sistemas consorciados sobre o monocultivo.

Comparando as associações no consórcio com os respectivos monocultivos do sorgo, verifica-se que nos sistemas 3,1 e 2 ocorreram os maiores rendimentos de proteína, que diferiram estatisticamente pelo teste " $\mathrm{t}$ " de contraste.

TABELA 4 - Resultados médios de matéria seca total sorgo e soja (kg/ha) obtidos no ensaio de efeitos de diferentes sistemas de corte, no rendimento forrageiro em consórcio e monocultivo, no ano agrícola 1999/00. UFLA, Lavras-MG, 2000.

\begin{tabular}{|c|c|c|c|c|c|c|}
\hline Tratamento & Sistema 1 & Sistema 2 & Sistema 3 & Sistema 4 & Sistema 5 & Mëdia \\
\hline AG 2002 x CAC-1 & $16970 * *$ & $25157 * *$ & $26146 * *$ & $6507^{\mathrm{ns}}$ & $8083^{\text {ns }}$ & 16571 \\
\hline AG 2002 X Conquista & $17352 * *$ & $21541 * *$ & $21351 * *$ & $6945^{\mathrm{ns}}$ & $7761^{\mathrm{ns}}$ & 14990 \\
\hline BR 601 x CAC-1 & $16173 * *$ & $19284 * *$ & $18646 * *$ & $7377^{\text {ns }}$ & $5677^{\mathrm{ns}}$ & 13431 \\
\hline BR 601 x Conquista & $13798 * *$ & $16541 * *$ & $16401 * *$ & $6259^{\mathrm{ns}}$ & $5485^{\mathrm{ns}}$ & 11696 \\
\hline AG 2002 x Soja & $17161 \mathrm{~B}$ & 23349 A & $23748 \mathrm{~A}$ & $6726 \mathrm{C}$ & $7922 \mathrm{C}$ & $15780 \mathrm{a}$ \\
\hline BR 601 x Soja & $14986 \mathrm{~B}$ & $17912 \mathrm{~A}$ & $17523 \mathrm{~A}$ & $6818 \mathrm{C}$ & $5581 \mathrm{C}$ & $12564 \mathrm{~b}$ \\
\hline CAC-1 x Sorgo & 16572 & 22220 & 22396 & 6942 & 6880 & $15002 \mathrm{a}$ \\
\hline Conquista X Sorgo & 15575 & 19041 & 18876 & 6602 & 6623 & $13343 \mathrm{~b}$ \\
\hline Média & $16073 \mathrm{~B}$ & 20629 A & 20636 A & $6772 \mathrm{C}$ & $6752 \mathrm{C}$ & 14172 \\
\hline \multicolumn{7}{|l|}{ Monocultivo } \\
\hline AG 2002 & \multicolumn{6}{|l|}{$10828 \mathrm{a}$} \\
\hline BR 601 & \multicolumn{6}{|l|}{$7263 \mathrm{~b}$} \\
\hline Média & \multicolumn{6}{|l|}{9045} \\
\hline \multicolumn{7}{|c|}{$\begin{array}{l}\text { Médias seguidas pela mesma letra, minúscula na coluna e maiúscula na linha, não diferem entre si pelo te } \\
\text { te de Scott Knott a } 5 \% \text { de probabilidade. }\end{array}$} \\
\hline
\end{tabular}

Ciênc. agrotec., Lavras. V.27, n.3, p.681-688, maio/jun., 2003 
TABELA 5 - Resultados médios de proteína bruta total de sorgo e soja (kg/ha) obtidos no ensaio de efeitos de diferentes sistemas de corte, no rendimento forrageiro em consórcio e monocultivo, no ano agrícola 1999/00. UFLA, Lavras-MG, 2000.

\begin{tabular}{lcccccc}
\hline \multicolumn{1}{c}{ Tratamento } & Sistema 1 & Sistema 2 & Sistema 3 & Sistema 4 & Sistema 5 & Mëdia \\
\hline AG 2002 x CAC-1 & $1876^{* *}$ & $1746^{* *}$ & $1846^{* *}$ & $1044^{\mathrm{ns}}$ & $982^{\mathrm{ns}}$ & 1498 \\
AG 2002 X Conquista & $1344^{* *}$ & $1445^{* *}$ & $1849^{* *}$ & $1011^{\mathrm{ns}}$ & $1094^{\mathrm{ns}}$ & 1348 \\
BR 601 x CAC-1 & $1596 * *$ & $1467 * *$ & $1637^{* *}$ & $1223^{\mathrm{ns}}$ & $986^{\mathrm{ns}}$ & 1381 \\
BR 601 x Conquista & $1339 * *$ & $1444^{* *}$ & $1611^{* *}$ & $958^{\mathrm{ns}}$ & $820^{\mathrm{ns}}$ & 1234 \\
\hline AG 2002 x Soja & 1610 & 1595 & 1847 & 1077 & 1038 & $1423 \mathrm{a}$ \\
BR 601 x Soja & 1468 & 1456 & 1624 & 1090 & 903 & $1308 \mathrm{a}$ \\
\hline CAC-1 x Sorgo & 1736 & 1606 & 1741 & 1133 & 983 & $1440 \mathrm{a}$ \\
Conquista X Sorgo & 1341 & 1444 & 1730 & 984 & 958 & $1291 \mathrm{a}$ \\
\hline Média & $1539 \mathrm{~A}$ & $1525 \mathrm{~A}$ & $1735 \mathrm{~A}$ & $1059 \mathrm{~B}$ & $970 \mathrm{~B}$ & 1365 \\
\hline
\end{tabular}

Monocultivo

AG 2002639 a

\begin{tabular}{ll} 
BR 601 & 776 a \\
\hline Média & 708
\end{tabular}

*Médias seguidas pela mesma letra, minúscula na coluna e maiúscula na linha, não diferem entre si pelo teste de Scott Knott a $5 \%$ de probabilidade.

*,** e ns - Contraste de " $t$ " entre consórcio e monocultivo do sorgo, significativo a $5 \%$, 1\% e nãosignificativo, respectivamente.

\section{CONCLUSÕES}

a) A utilização dos cortes, obedecendo ao estádio farináceo do sorgo (sistema 3), proporcionou os maiores rendimentos de massa verde total, matéria seca total e proteína bruta total.

b) A associação do sorgo AG 2002 e a soja CAC-1 apresentou os maiores rendimentos de massa verde total, matéria seca total e proteína bruta total.

c) Em monocultivo, o híbrido AG 2002 apresentou maior rendimento de matéria verde e matéria seca total.

\section{REFERÊNCIAS BIBLIOGRÁFICAS}

CARDOSO, D. A. de B. Maximização da exploração da soja (Glycine max (L.) Merrill). Efeito do espaçamento, da densidade e altura de corte na produção de feno e grãos da rebrota, cv. Cristalina. $1985.83 \mathrm{f}$.
Dissertação (Mestrado em Fitotecnia) - Escola Superior de Agricultura de Lavras, Lavras.

CARNEIRO, A. M.; RODRIGUEZ, M. N. Efeitos da consorciação de milho com leguminosas anuais na produção e qualidade de material para a ensilagem. Arquivos da Escola de Veterinária da UFMG, Belo Horizonte, v. 30, n. 2, p. 219-227, 1978.

CARNEIRO, A. M.; RODRIGUEZ, M. N. Influência da leguminosa na qualidade da silagem de milho. Arquivos da Escola de Veterinária da UFMG, Belo Horizonte, v. 32, n. 2, p. 415-420, 1980.

CARvalho, A. J. C. de. Comportamento de genótipos de soja em monocultivo e em consórcio com o milho de portes diferentes. 1993. 60 f. Dissertação (Mestrado em Fitotecnia) - Escola Superior de Agricultura de Lavras, Lavras. 
COMISSÃO DE FERTILIDADE DO SOLO DO ESTADO DE MINAS GERAIS. Recomendações para o uso de corretivos e fertilizantes em Minas Gerais: $4^{\text {a }}$ aproximação. Lavras: EPAMIG, 1989. 159 p.

EVANGELISTA, A. R. Efeito da associação milhosoja na produção de massa verde e no valor nutritivo da silagem. 1980. 47 f. Dissertação (Mestrado em Fitotecnia) - Universidade Federal de Viçosa, Viçosa.

FEHR, W. R.; CAVINESS, C. E. Stages of soybean development. Ames: Iowa State University, 1977. 12 p. (Special Report, 80).

OLIVEIRA, A. F. Efeito da associação de cultivares de milho (Zea mays L.) e soja (Glycine max (L.) Merrill) no rendimento e valor nutritivo da forragem. 1986a. 81 f. Dissertação (Mestrado em Fitotecnia) - Escola Superior de Agricultura de Lavras, Lavras.

OLIVEIRA, J. M. de. Rendimento, qualidade da forragem e valor nutritivo das silagens de sorgo forrageiro e granífero consorciado com soja. 1986b. $57 \mathrm{f}$. Tese (Doutorado em Zootecnia) - Universidade Federal de Viçosa, Viçosa.

OLIVEIRA, J. N. S. Maximização da exploração da soja. Efeito da época de corte e adubação nitrogenada em cobertura na produção de feno e grãos oriundos da rebrota cv. Cristalina. 1987. 85 f. Dissertação (Mestrado em Fitotecnia) - Escola Superior de Agricultura de Lavras, Lavras.
REZENDE, P. M. de. Capacidade competitiva de cultivares de milho e soja consorciados em função da produção de grãos e forragem. 1995. 154 f. Tese (Doutorado em Fitotecnia) - Universidade Federal de Lavras, Lavras.

REZENDE, P. M. de. Maximização da exploração da soja. I. Efeito do corte aos 60 dias na produção de feno e grãos da Rebrota. Pesquisa Agropecuária Brasileira, Brasília, v. 19, n. 3, p. 329-336, mar. 1984.

REZENDE, P. M. de; FAVORETTO, C. R. S. Maximização da exploração da soja [Glycine max (L.) Merrill]. IV. Efeito da altura de corte no rendimento de feno e grãos de Rebrota. Pesquisa Agropecuária Brasileira, Brasília, v. 22, n. 11/12, p. 1189-1193, nov./dez. 1987.

REZENDE, P. M. de; TAKAHASHI, S. Maximização da exploração da soja. IX Efeito do sistema de cortes na seleção de cultivares para produção de feno. Ciência e Prática, Lavras, v. 14, n. 1, p. 44-55, jan./abr. 1990.

SILVA, A. G da. Produção de forragem de cultivares de sorgo e soja, consorciadas na linha, em dois sistemas de corte. 1998. 80 p. Dissertação (Mestrado em Fitotecnia) - Universidade Federal de Lavras, Lavras.

SILVA, A. G. da; REZENDE, P. M. de; ANDRADE, L. A de B.; EVANGELISTA, A. R. Produção de forragem de cultivares de soja e híbridos de sorgo, consorciadas na linha, em dois sistemas de corte. Ciência Rural, Santa Maria, v. 30, n. 6, p. 933-939, 2000. 